\title{
Hume and the Perception of Spatial Magnitude
}

\author{
Edward Slowik
}

\begin{abstract}
:
This paper investigates Hume's theory of the perception of spatial magnitude or size as developed in the Treatise, as well as its relation to his concepts of space and geometry. The central focus of the discussion is Hume's espousal of the "composite" hypothesis, which holds that perceptions of spatial magnitude are composed of indivisible sensible points, such that the total magnitude of a visible figure is a derived by-product of its component parts. Overall, it will be argued that a straightforward reading of this hypothesis fails to do full justice to the complexity of Hume's theory of spatial perception and geometry, and that a more adequate treatment must also admit an important role for the more direct process of spatial magnitude perception which he dubs "intuition".
\end{abstract}




\title{
Hume and the Perception of Spatial Magnitude
}

\author{
Edward Slowik
}

Among the current topics in Hume scholarship witnessing an upsurge in attention, few can match the inherent complexities associated with his doctrine of space, that often neglected and occasionally maligned theory put forth in Book I, Part II, of the Treatise. 1 Yet, despite this increase in academic interest, Hume's concept of spatial magnitudei.e., the spatial size or magnitude of visible and tangible figures 2 - as opposed to his more general notion of space, has not attracted the same degree of attention. Even if commentators agree that Hume took the idea of space to be an idea derived from "the impressions of color'd points, dispos'd in a certain manner" (T 1.2.3.3), this fact does not tell us what measures the distance between these impressions (perceptions), or what psychological processes and empirical properties are involved in the act of determining size or magnitude. If one bears in mind that the concept of spatial magnitude is also intimately connected with the status of geometry, and the debate on whether Hume endorsed a synthetic or analytic a priori account of geometrical knowledge, the failure to study exhaustively Hume's concept of distance becomes all the more astonishing.

Finding a clear and comprehensive analysis of this issue in the existing Humean literature is quite difficult, but there would appear to be two seemingly polar opposite positions between which most commentators fall. First, there is the "composite" hypothesis, as we shall call it, which places a considerable emphasis on the aggregate structure of the "atomic" visual points that comprise larger extended figures (Broad, Falkenstein, Jacquette)3. On the other hand, there is an interpretational stance that 
conceives spatial magnitude as a given, non-composite feature of our individual perceptions (possibly Waxman)4. The difference between these, respectively, "bottomup" and "top-down" approaches to perceived spatial magnitude could have far-reaching ramifications for the Humean foundations of geometry and mathematics.

In what follows, I argue that Hume regarded spatial magnitude as a directly perceived, non-composite aspect of visual experience. After examining the details of Hume's theory of space in section 1, section 2 focuses on a series of passages from the Treatise that reveal the intricate nature of Hume's reflections on spatial magnitude, as well as its role in his more general theory of space. Finally, in section 3 , the importance of Hume's spatial theory is examined within a broader historical context.

\section{Space in the Treatise: A Concise Overview}

Hume's lengthy analysis of space, extension, and geometry, appears early in the Treatise, most likely prompted by a perceived need to explain how the origin and function of this class of ideas does not undermine his empiricism (i.e., his more general theory of ideas, as espoused in the preceding Part I, of Book I). On the whole, Hume reasons that our idea of extension (space) is acquired, not from simple sense impressions, but rather from compound sense impressions: "that compound impression, which represents extension, consists of several lesser impressions, ..." (T 1.2.3.15). Early in the

Treatise, Hume lays out the distinction between the two types of perceptions:

Simple perceptions or impressions and ideas are such as admit of no distinction nor separation. The complex are the contrary to these, and may be distinguish'd into parts. Tho' a particular colour, taste, and smell are qualities all united together in this apple, 'tis easy to perceive they are not the same, but are at least distinguishable from each other. ( $\mathrm{T}$ 1.1.1.2) 
Hume's claim that a compound idea "may be distinguished into parts" is a direct analogue of his claim that "space or extension consists of a number of co-existent parts dispos'd in a certain order, and capable of being at once present to the sight or feeling" ( $\mathrm{T}$ 2.3.7.5) The tenor of Hume's account would thus seem to attribute a "part-whole" relationship to complex impressions. Just as the qualities of a particular taste, color, smell, are "united together in the apple", thereby forming an inner-relationship of qualities, the simple impressions of extension are likewise united in our compound impression of extension.

Furthermore, Hume's belief that the idea of extension is obtained directly, or immediately, seems to rule out the faculties of imagination and abstract reason (as in "distinctions of reason") from the process of magnitude perception.

The Table before me is alone sufficient by its view to give me the idea of extension. This idea, then, is borrow'd from, and represents some impression, which this moment appears to the senses. But, my senses convey to me only the impressions of color'd points, dispos'd in a certain manner. If the eye is sensible of anything farther, I desire it may be pointed out to me. But if it is impossible to shew anything farther, we may conclude with certainty, that the idea of extension is nothing but a copy of these color'd points, and of the manner of their appearance. ( $\mathrm{T}$ 1.2.3.4)

Such claims as, "the table before me is alone sufficient by its view to give me the idea of extension", and, "the idea of extension is nothing but a copy of these color'd points", would appear to support the thesis that the perception of extension is direct: i.e., that our impressions are not first mediated or interpreted by way of a higher mental faculty that somehow constructs or fashions our perceptions of extension. The lack of any reference in the Treatise to the role of imagination or abstraction in the perception of extension also supports this conclusion (although this remains a contentious issue among commentators). 5 However, Hume does allow imagination and distinctions of reason to 
play a significant part in the formulation of our abstract conception of space, as when we conceive of extension apart from any specific color or extended body. Despite the fact that our original impressions of extension are conjoined with the colors of the extended bodies, Hume holds that we can "omit the peculiarities of colour, as far as possible, and found an abstract idea merely on that disposition of points [that constitute the extended body]. .." (T 1.2.3.4).

Turning to the central components of the theory, Hume puts forward a notion of space (extension) as derived from "the impressions of color'd points, dispos'd in a certain manner" (T 1.2.3.4):

The idea of space is convey'd to the mind by two senses, the sight and touch; nor does anything ever appear extended, that is not either visible or tangible. That compound impression, which represents extension, consists of several lesser impressions, that are indivisible to the eye or feeling, and may be call'd impressions of atoms or corpuscles endow'd with colour and solidity. ( $\mathrm{T}$ 1.2.3.15)

The parts, into which the ideas of space and time resolve themselves, become at last indivisible; and these indivisible parts, being nothing in themselves, are inconceivable when not filled with something real and existent. (T 1.2.4.2).

Two additional features of Hume's theory are evident in these passages: first, his "relationism" concerning our idea of space; and second, his "finitism" concerning the parts of extension, which he often refers to as "points" or "atoms". As for the first, Hume insists that "we can form no idea of a vacuum, or space, where there is nothing tangible or visible" (T 1.2.5.1), and "we have no idea of any real extension without filling it with sensible objects. .." (T 1.2.5.27). This approach amounts to a sort of phenomenalist version of a relational theory of space, because it implies that we can have no idea of space if we do not receive any visual or tactile impressions/perceptions.6 Secondly, Hume furnishes a lengthy polemic against the infinite divisibility of extension, a section of Part 
II probably inspired by similar arguments in Bayle and Berkeley.7 Although a thorough treatment of this issue lies outside the scope of the present essay, a brief summary of Hume's argument can be given: because the human mind cannot obtain "a full and adequate conception of infinity", and since that which is infinitely divisible contains an infinite number of parts, it must follow that "the idea, which we form of any finite quality, is not infinitely divisible" (T 1.2.1.2).

\section{Magnitude and The Composite Hypothesis}

2.1. Minimal Sensibles and Composite Structure. One of the predominant concerns of recent investigations into Hume's account of space is the role played by the indivisible impressions of extension, especially the minimally visible points that comprise visual extension. Are spatial magnitudes formed, or built-up, out of the minimal visible points, such that the magnitude of an entire extended figure is the mere sum of the separate contributions of its composite minimals? I will dub this foundationalist view the “composite hypothesis". On the whole, the published literature on Hume's doctrine of space fails to address explicitly the question as to whether or not he endorsed the composite hypothesis. However, it would appear that the composite hypothesis is tacitly presumed by several prominent commentators, who suppose that for Hume the total magnitude of a visible figure can be reduced to a summation of each separate minimal's magnitude. Falkenstein, for instance, claims that "there must in fact be only finitely many points given at the minimal degree of separation in any compound idea, and increasing the number must increase the size of the idea" (200). This explanation apparently holds for impressions, as well: "The size of impressions and ideas is a function of the number 
of minimally visible or minimally tangible points they contain" (199). Dale Jacquette seems to make a similar point: "the idea seems to be. . that by putting two or more such indivisibles together, even by the very slightest overlapping, the subject will experience an impression that is phenomenally divisible and extended" (1996, 72-73).

Naturally, Hume's account of the minimal visibles is crucially important in this context, for it provides one of the first instances of an alleged "decomposition" of a large (visually) extended object into its most elementary indivisible components. In section I (of Part II), Hume explains that if an ink spot is placed on a sheet of paper, and a person focuses on the ink spot while continuously moving backwards, then ultimately a position will be reached where "'tis plain, that the moment before it vanish'd the image or impression was perfectly indivisible" (T 1.2.1.4). At this location relative to the object, he reasons, the impressions caused by light rays (emanating from the object) "[are] reduced to a minimum, and [are] incapable of any further diminution" (T 1.2.1.4). All this seems to imply that a perception of an extended body contains a number of such indivisible minimals added together. 8

There is a good deal of circumstantial evidence in the Treatise that suggests that it does support the composite hypotheses of spatial magnitude. For example, Hume claims that the mind arrives "at an end in the division of its ideas [of any finite quality]" (T 1.2.1.2), and that the view correlating the size of a line or surface to its total number of indivisible points is "just, as well as obvious" (T 1.2.4.19). In discussing the contiguity of these minimal points, furthermore, he reasons that "a blue and a red point may surely lie contiguous to one another without any penetration or annihilation" (T 1.2.4.6), a conclusion that would seem to imply, albeit tentatively, that the contiguous positioning of 
these points has doubled the size of the corresponding impression (since their combination is exactly twice the size of either minimal when perceived separately).

Finally, the mind is ascribed the ability, presumably via the faculty of imagination, to augment a minimal idea of extension by repeated addition:

I first take the least idea I can form of a part of extension, and being certain that there is nothing more minute than this idea, I conclude, that whatever I discover by its means must be a real quality of extension. I then repeat this idea once, twice, thrice, $\& c$. and find the compound idea of extension, arising from its repetition, always to augment, and become double, triple, quadruple, $\&$ c. till at last it swells up to a considerable bulk, greater or smaller, in proportion as I repeat more or less the same idea. ( $\mathrm{T}$ 1.2.2.2)

Given explanations of this sort, the appeal of the composite hypothesis is quite understandable: the repetition—i.e., cumulative addition—of a minimal idea is said to cause me to judge the compound idea to become double, triple, etc., thereby justifying the view that the perception of a figure as having a large magnitude just is the perception of it as having a large number of parts, and that the perception of one figure as being larger than another is the perception of it as having a larger number of parts.

\subsection{Imagination and Constructive Acts. Nevertheless, the problem with the} evidence just presented in favor of the composite hypothesis is that it only pertains to the idea of space as deliberately processed in the imagination through a creative or constructive act: e.g., the mind arrives "at an end in the division of its ideas", or "I repeat this idea once, twice, thrice, etc." There is no reference to the spatial content or information encoded in our ordinary compound impressions and ideas of sensation (such as colored points "disposed in a certain manner"), where the role played by the faculty of imagination remains unclear. The ability of the mind to augment or divide its ideas of space involves the imagination in an elaborate exercise of addition or division. Hume 
regards all abstract ideas of space, including distance, as constructed in this fashion (T 1.1.5; see, also, section 1 and endnote 5). Yet, the discussion of the philosophical relations, of which space and distance form a part, fails to mention how our nonimaginary, sensible (visual and tactile) compound impressions and ideas of extension are processed by the mind, hence the passages just quoted (section 2.1) must remain inconclusive.

Furthermore, the Humean concept of "intuition" greatly complicates any inference to a creative, enumerative act at the level of the ordinary compound impressions and ideas of sensible extension. Hume declares that several of the philosophical relations of ideas "are discoverable at first sight, and fall more properly under the province of intuition than demonstration" ( $\mathrm{T}$ 1.3.1.2). Ultimately, the relation "proportions in quantity and number" is included in this category, since the knowledge obtained concerning the relative equality (or congruence) of small portions of extension is "in many cases certain and infallible" ( $\mathrm{T}$ 1.2.4.22). In this section of the Treatise, Hume is concerned with demonstrating that, despite the overall fallibility of our judgments of equality, there are cases when we can safely make such comparative judgments of object size, since "we perceive an impossibility of falling into any considerable error" (T 1.3.1.3). The closer the objects approach in size, the more unreliable these judgments become, which prompts Hume to remark that "where the difference [in size] is very great and remarkable", we are on better grounds to "observe a superiority or inferiority betwixt any numbers, or figures" (T 1.3.1.3). The fact that he categorizes congruence judgments as "intuitive" mental acts is the relevant point at issue, however. Hume follows the precedent of many other Early Modern philosophers in 
conceiving the faculty of intuition as a means of obtaining direct knowledge (in this case, of the relations of size) without any intervening ideas or mental acts. In David Owen's description, such relations "can be known immediately, simply by comparing the related ideas. . . intuition requires no steps of reasoning: no intermediate ideas need be found."9 The exact interrelationship of Humean intuition and imagination, if any, is a complex issue 10, but a few general conclusions can be put forth with reasonable assurance: if the knowledge of the relative size of small visible figures is "comprehended in an instant" (T 1.3.1.3), then it is no longer clear to what extent the normal interpretation of the faculty of imagination can be ascribed to this process of magnitude determination. Specifically, since the enumeration of points in the composite hypothesis (see the passage quoted above, T 1.2.2.2) appears to implicate the mind in an intentional, non-instantaneous, creative act of idea construction, any instantaneous determination of magnitude congruence would appear to run counter to the composite hypothesis. Therefore, even if the imagination is involved in the act of intuition - and it is not clear that it is involved, of course - it is not the correct form of imaginative act as required by the composite hypothesis.

2.3. Hume's Counter-Argument. If the objections raised thus far do not necessarily comprise a major threat to the composite hypothesis, there is still one serious obstacle that lies in its path. In section IV (of Part II), Hume reasons that the estimation of magnitude, or length, among two figures cannot be based on a process that equally pairs off their aggregate points:

I first ask mathematicians, what they mean when they say one line or surface is EQUAL to, or GREATER, or LESS than another? ... They need only reply, that lines or surfaces are equal, when the number of points in each are equal; and that as the proportion of the number varies, the proportion of the lines and surfaces is also 
vary'd. But tho' this answer be just, as well as obvious; yet I may affirm, that this standard of equality is entirely useless, and that it never is from such a comparison we determine objects to be equal or unequal with respect to each other. For as the points, which enter into the composition of any line or surface, whether perceiv' $d$ by the sight or touch, are so minute and so confounded with each other, that 'tis utterly impossible for the mind to compute their number, such a computation will never afford us a standard, by which we may judge of proportions. No one will ever be able to determine by an exact numeration, that an inch has fewer points than a foot, or a foot fewer than an ell or any greater measure; ... . (T 1.2.4.18-19)

If, as the composite hypothesis maintains, magnitude is determined by the total number of points, then an inability to compute that total number renders the hypothesis "useless". The structure of Hume's argument takes a "reductio" form: (i) assume that the perceived magnitude of a figures is determined by enumerating the total number of points (the composite hypothesis), (ii) then demonstrate that it leads to the conclusion that the magnitude of the figure cannot be determined (since the total number cannot be computed), but (iii) since it obviously the case that magnitude can be discerned, (iv) the composite hypothesis thus cannot account for our ability to determine magnitude. It should be noted that this argument was fairly common during Hume's time, for it appears in the work of such natural philosophers as Berkeley (see endnote 7). Part of the importance of Hume's version of the argument, especially given the context of our investigation, is that he specifically mentions the underlying principle of the composite hypothesis "that as the proportion of the number varies, the proportion of the lines and surfaces is also vary'd", and, more importantly, that the mind must "compute their number" as a means of determining their magnitude — and this last step would appear to single out the composite hypothesis for criticism. Slightly later in Hume's discussion, a similar argument is leveled at the attempts to define "congruity" by the mutual contact of parts: 
There are some, who pretend, that equality is best defin'd by congruity, and that any two figures are equal, when upon the placing of the one upon the other, all their parts correspond to touch each other. In order to judge of this definition let us consider, that since equality is a relation, it is not, strictly speaking, a property in the figures themselves, but arises merely from the comparison, which the mind makes betwixt them. If it consists, therefore, in the imaginary application and mutual contact of parts, we must at least have a distinct notion of these parts, and must conceive their contact. Now 'tis plain, that in this conception we wou'd run up these parts to the greatest minuteness, which can possibly be conceiv'd; since the contact of large parts wou'd never render the figures equal. But the minutest parts we can conceive are mathematical points; and consequently this standard of equality is the same with that deriv'd from the equality of the number of points, which we have already determin'd to be a just but an useless standard. (T 1.2.4.21)

In defense of the composite hypothesis, Falkenstein responds to these arguments by distinguishing between the minds ability to enumerate the points that comprise an idea of a figure, and the objective fact that the idea of the figure actually contains a definite number of points: "To say that a small figure may not be known 'by an exact enumeration' to contain fewer points than any larger figure is not the same as to say that it does not in fact consist of fewer points than any larger figure. The latter point is one that Hume is committed to" (200). He ultimately concludes, therefore, that "greater numbers of points in fact make the idea bigger, even though we may not be able to count them up and so determine by an 'exact enumeration' that any given figure in fact has more points in it than any other" (200).

On the whole, Falkenstein is correct in making the crucial distinction between the number of points that a figure contains and the manner by which the magnitude of extended figures is computed. The problem with this form of response, of course, is that it admits that the mind's process of determining magnitude and congruity is not a result of adding the individual component parts. If the mind does not proceed in this manner, then how does it determine magnitude? In particular, if the mind does not rely on the 
computation of the indivisible points to measure size, then of what use is the composite hypothesis in explaining the perception of magnitude? On the composite hypothesis, the problem is even more acute, since a somewhat troublesome dichotomy would appear to surface in the mind's capacity to estimate magnitude: on the one hand, there are the total number of points contained in the idea of a figure - points that objectively determine its magnitude, but which the mind cannot compute - and, on the other hand, there is the mind's ability to determine the magnitude of the figure by a process somehow independent of computing the total number of its aggregate points. But, if the mind can determine magnitude without the need of a point summation, then why introduce the composite hypothesis at all? What work is it doing?

In short, the problem with the composite hypothesis would seem to lie in an apparent disconnect, or breakdown, between its ontology of spatial ideas/impressions and the psychological process of magnitude perception that should naturally follow from this ontology. On the composite hypothesis, the ontology of spatial ideas relies on an aggregate point summation: as the number of minimal visibles is increased, the corresponding magnitude of the compound idea (or impression) is increased in a proportionate manner. If this hypothesis is correct, however, then one would expect that the perception of the magnitude of a spatial idea could be analyzed, or dissected, so that this increase in minimal visibles could likewise be perceived proportionately. Yet, Hume's insistence that the perception of a large visible figure cannot be shown to possess more minimal visibles (than a simultaneously perceived smaller visible figure) would seem to imply that such additions of minimals cannot be perceived in a directly proportionate way; or, in other words, that it is not possible to perceive the individual 
contribution of each minimal to the overall magnitude of the aggregate, although the individual contribution of each minimal point is central to the ontological account of spatial ideas/impressions. The psychological process of magnitude perception that is seemingly entailed by the ontology of the composite hypothesis is, therefore, rejected or dismissed in the Treatise. In the concluding section of this essay, nevertheless, I will hint at an interpretation that tries to incorporate much of the ontological content of the composite hypothesis without running afoul of Hume's rejection of its implied psychology of magnitude perception.11

\section{Magnitude and Geometry}

3.1. Relations and the Arithmetic/Geometry Debate. If the composite hypothesis does not capture the full complexity of Hume's philosophy of spatial magnitude perception, are there alternative interpretations of the hypothesis that do a better job of reconciling the disparate elements surveyed thus far? While the role of intuitive and nonintuitive knowledge is essential to answering this question, it is necessary to investigate first Hume's theory of relations, especially the distinction between "place" and "quantity". First, Hume classifies "relations of place (space, distance, etc.)" as nonintuitive since the "contiguity and distance between two objects may be chang'd merely by an alteration of their place, without any change on the objects themselves or their ideas; ..."'(T 1.3.1.1). In other words, relations of place cannot be determined by analysis of the objects and their properties alone, but depend upon the relations between those prior objects and bodily properties (i.e., epistemologically prior). In contrast, other philosophical relations, such as "proportions of quantity or number", can be ascertained 
with immediate and certain accuracy, since they depend "entirely on the ideas, which we can compare together" ( $\mathrm{T}$ 1.3.1.1). Relations of quantity and number, accordingly, can only be altered by a direct change in the bodies and their properties (unlike the relations of place, whose spatial properties can change even though the bodies and their properties remain invariant). For instance, if a visible figure is perceived to be larger than a second, then this relationship (of "quantity") can only be modified by changing the size of one, or both, of the figures. In the relations of "place", on the other hand, one can constantly alter the relation (e.g., "x is left of y") without affecting any of the "intrinsic" properties of the bodies/figures involved.

Besides attesting to a strong brand of relationism (at the phenomenal level; see endnote 6), Hume's contrasting approach to the relations of place and quantity parallels another dichotomy evident in Part III, section I of the Treatise; namely, the difference in epistemological status accorded to, respectively, arithmetic and geometry. Hume was well acquainted with this problem in the "foundations of mathematics" (as we call it today), since it constituted a major philosophical debate in the seventeenth and eighteenth centuries, and even involved some of the most eminent mathematicians and scientists of the period (such as Barrow and Wallis). In brief, one school (Barrow) held that geometry formed the more fundamental and essential branch of mathematics, with arithmetic constituting a nominalist abstraction derived from geometry. Another school (Wallis) adopted the exact opposite view, taking arithmetic as primary and geometry as derivative.12 Hume apparently favored the former position, with certain qualifications (as will be discussed below), although it is not evident in his summary of the respective certainties that accrue to geometric and arithmetic operations: 
Geometry, or the art, by which we fix the proportions of figures; tho' it much excels both in universality and exactness, the loose judgments of the senses and imagination; yet never attains a perfect precision and exactness. Its first principles are still drawn from the general appearance of the objects; and that appearance can never afford us any security, when we examine the prodigious minuteness of which nature is susceptible. Our ideas seem to give a perfect assurance, that no two right lines can have a common segment; but if we consider these ideas, of the two lines, and that where the angle they form is extremely small, we have no standard of a right line so precise as to assure us of the truth of the proposition. ...

There remain, therefore, algebra and arithmetic as the only sciences, in which we can carry on a chain of reasoning to any degree of intricacy, and yet preserve a perfect exactness and certainty. We are possest of a precise standard, by which we can judge of the equality and proportion of numbers; and according as they correspond or not to that standard, we determine their relations, without any possibility of error. When two numbers are so combin'd, as that the one has always an unite answering to every unite of the other, we pronounce them equal; and 'tis for want of such a standard of equality in extension, that geometry can scarce be esteem'd a perfect and infallible science. (T 1.3.1.4-5)

Like Berkeley before him, Hume maintains a highly visual, image-based or idea-based theory of the mental processes associated with mathematics and geometry. Our knowledge of geometric propositions, on this view, is thus derived from "appearances", presumably visual, which explains our inability to obtain precision and certainty in the conclusions we draw from them.13

As regards arithmetic (and algebra), on the other hand, Hume's reference to "a precise and exact standard", and the fact that two numbers can be compared such that "one has always an unite answering to every unite of the other", would seem to suggest that arithmetic is not closely bound to an image-based mental function: that is, arithmetic is more conceptual, and less visual — and since visual images manifest a geometric shape, it thus follows that mathematics is less geometric. This interpretation of the evidence is plausible, but Hume's nominalist tendencies in mathematics would seem to undercut its force. Earlier in section II, Hume quite clearly ties mathematics, as "number", to the more 
visual-geometric entities he refers to as "unite", thereby linking this discussion with his later use of "unite" in the passage quoted above:

'Tis evident that existence, in itself belongs only to unity, and is never applicable to number, but on account of the unites, of which number is composed. ... That term of unity [such as "twenty men are an unite"] is merely a fictitious denomination, which the mind may apply to any quantity of objects it collects together; nor can such an unity any more exist alone than number can, as being in reality a true number. But the unity, which can exist alone, and whose existence is necessary to that of all number, is of another kind, and must be perfectly indivisible, and incapable of being resolved into any lesser unity. ( $\mathrm{T}$ 1.2.2.3)

In this quite remarkable excerpt, Hume seems to place the very foundations of number and unity, and consequently arithmetic, on the groundwork of his theory of indivisible minimals. The indivisible points constitute the nominalist basis of all mathematics, moreover, since the minimals also form visible figures (as "points disposed in a certain manner"). 14

3.2. Intuition and Sensible Figure: Towards a Synthesis. If algebra and arithmetic "preserve a perfect exactness and certainty", in contrast to geometry, the decisive factor underlying this dichotomy would appear to be the cognitive process that Hume labels "intuition". As described in section 2.2, Hume reckons that various philosophical relations "are discoverable at first sight, and fall more properly under the province of intuition than demonstration" (T 1.3.1.2). The exact function of intuition in mathematics is disclosed in the same context, while explaining the relations of quantity or number: "As to equality or any exact proportion, we can only guess it from a single consideration; except in very short numbers, or very limited portions of extension; which are comprehended in an instant, and where we perceive an impossibility of falling into any considerable error" ( $\mathrm{T}$ 1.3.1.3) One might infer, given the discussion above, that the "limited portions of extension" which Hume mentions in this passage only pertain to 
indivisible minimals, but an earlier section clearly identifies the relative judgments of the size of extended visibles (if there is an appreciable size difference among the figures) as capable of certain knowledge as well:

'Tis evident, that the eye, or rather the mind is often able at one view to determine the proportions of bodies, and pronounce them equal to, or greater or less than each other, without comparing the number of their minute parts. Such judgments are not only common, but in many cases certain and infallible. When the measure of a yard and that of a foot are presented, the mind can no more question, that the first is longer than the second, than it can doubt of those principles, which are the most clear and self-evident. (T 1.2.4.22)

This paragraph follows Hume's apparent rejection of the composite hypothesis as applied to congruity (as quoted in section 2.3). In combining these scattered references to the role of intuition in mathematics, the following picture begins to emerge: If two or more visible (and presumably tangible) figures are of sufficient size to be compared "at one view", or "comprehended in an instant", then certain knowledge of their relative magnitudes can be ascertained (bearing in mind, once again, that the figures are not too close in size). Specifically, the figures must not be too large or too small to exceed the capacity of our visual (or tangible) field to take in the whole object, or objects, immediately and distinctly, and thereby render a judgment of relative size based only on that single perception - i.e., provide determinations of greater than, equal to, or less than, which fall under the heading of congruence, from one impression/idea. This interpretation is corroborated by Hume's lengthy explanation of the uncertainties inherent to most geometric reasoning: "[Geometry's] first principles are still drawn from the general appearance of the objects; and that appearance can never afford us any security, when we examine the prodigious minuteness of which nature is susceptible" (T 1.3.1.4). In other words, once the measurements of the geometric relations of size, magnitude, 
congruence, etc., go beyond what we can immediately determine in the visible figures themselves - and Hume is largely preoccupied with the imperceptible realm of the infinitesimally small—-the certainties obtained with the larger extended visibles no longer hold: "Our ideas seem to give a perfect assurance, that no two right lines can have a common segment; but if we consider these ideas, of the two lines, and that where the angle they form is extremely small, we have no standard of a right line so precise as to assure us of the truth of the proposition" (T 1.3.1.4).

With the disclosure of the important role of intuition, we are finally in a position to bring together many of the loose threads in our analysis of spatial magnitude and the composite hypothesis. For Hume, spatial magnitude is a perception that allows intuitively certain knowledge when confined to the relations of medium sized or significantly different visible or tangible figures; that is, for "very limited portions of extension; which are comprehended in an instant, and where we perceive an impossibility of falling into any considerable error [i.e., by the figures being too close in size, which greatly increases the possibility of error in our judgments]" (T 1.3.1.3) Conjoining this theory with his nominalist approach to algebra and arithmetic (as explored in section 3.1), the most plausible interpretation of Hume's theory of spatial magnitude perception should thus regard the perception of extended visibles (tangibles) as primary, such that we do not directly perceive the abstract composition or structure of the separate minimals that form extended figures. Put simply, we perceive extended figures: we do not perceive the individual non-extended minimals arranged in a certain structural order. This may seem a trivial observation to make, but now we are in a position to defend this obvious claim against the advocates of the composite hypothesis who may insist, in a strict reductivist 
manner, that "perceiving an extended figure" can be simply and completely explained as "perceiving a collection of non-extended minimal visibles arranged in a certain structural order”. If arithmetical concepts (such as numbers, addition, etc.) are ideas conceptually abstracted from our perceptions of extended figures, and quite possibly from the indivisibles themselves, then any formulation of the composite hypothesis that treats the magnitude of these figures as composite or aggregate structures formed through the perceptual addition of the more basic indivisibles seems rather misguided. As a notion derived from the perception of visibles, "addition" cannot itself be available for the psychological/perceptual construction of the visibles - to argue otherwise is to open up Hume's entire theory of spatial perception to the charge of circularity.

\section{Conclusion}

All told, the composite hypothesis is faced with a difficult task: it must harmonize Hume's ontology of spatial ideas/impressions, which relies on an aggregate structure of minimal points, with his psychology of the perception of spatial magnitude, which apparently does not rely on the perception of this aggregate structure. In response, proponents of the composite hypothesis might deny one of the key premises in the argument put forth against their view; namely, the assumption that the ontological structure of spatial ideas requires an exact correlate at the psychological level of magnitude perception. As presented in section 2.3, the case against the composite hypothesis largely rested on Hume's assertion that the magnitude or congruity of a pair of visible figures can not be ascertained by a process of point enumeration (or by pairing off the visible points, etc.). It could be claimed, as a counter-argument, that the composite 
structure of the minimals at the ontological level need not itself play a direct, or obvious, role in explaining the perception of magnitude; rather, it is just a primitive fact that the addition of more minimal points brings about (produces, creates, etc.) the perception of a larger visible figure. In effect, the composite hypothesist could respond by invoking the old axiom that "the whole [perception] is greater than the sum of its parts [the minimal points conjoined together]", while simultaneously appealing to well-known instances of a perceived increase in size resulting from an addition of unobservable smaller entities (e.g., I perceive that the plant is bigger despite the fact that the added cells, etc., are not themselves visible to the naked eye).

While this form of defense has its merits, and may well be what Hume actually intended, it harbors a significant problem. The lack of a parallel structure in our perceptions of material objects and their underlying ontology is acceptable (if still mysterious) due to the fact the underlying ontology is a physical, and not mental, property of the world, whereas perceptions are normally classified as mental content. In the case of Hume, unfortunately, this type of mind-body dualism of the perception of material objects cannot be upheld: the aggregate structure of points and the consequent judgment of perceived magnitude are both mental items (or, alternatively, they are both physical items, if one favors a physicalist interpretation of Hume's talk of mental content). Therefore, one would expect a direct interrelationship or interconnection between a given aggregate structure of minimal impressions/ideas and the ensuing psychological process of magnitude judgment associated with that aggregate structure. Hume does not tell us how the ontological level of his theory of space perception links up 
with the psychological process of magnitude judgment, hence the composite hypothesis must remain a problematic attempt to bridge this philosophical divide. 15

\section{ENDNOTES}

1 D. Hume, A Treatise of Human Nature, edited by D. F. Norton and M. J. Norton (Oxford: Oxford University Press, 2000). Citations from the Treatise will be designated by "T" followed by the book, part, section, and paragraph.

2 The "magnitude" that is under investigation in this paper is one that abstracts from the more general concerns over the distance between an object and the observer. In the Early Modern period, questions were raised about whether this distance, and consequently the magnitude of objects insofar as it varies with this distance, is an immediate object of perception. Hume was not particularly concerned with this issue, however. His interest centered upon the more fundamental question of how it is that we perceive objects as having any magnitude at all, and with what leads us to perceive one object as having a greater magnitude than another. These are the questions that constitute the subject of this investigation.

3 C. D. Broad, "Hume's Theory of Space", Proceedings of the British Academy, vol. 47, 1961, p. 161-176;

L. Falkenstein, "Hume's on Manners of Dispositions and the Ideas of Space and Time”, Archiv fur Geschichte der Philosophie, vol. 79, 1997, p. 179-201; D. Jacquette, "Hume on Infinite Divisibility and Sensible Extensionless Indivisibles", Journal of the History of Philosophy, vol. 34, 1996, p. 61-78.

4 W. Waxman, "The Psychologistic Foundation of Hume's Critique of Mathematical Philosophy”, Hume Studies, vol. 22, 1996, p. 123-167. This view of Hume's theory of extended visible figure has not gathered as much support as the opposite (summation of indivisibles) approach. 
5 Some commentators have attempted to make sense of Hume's theory of space (and time) by assigning a fundamental role to these higher mental faculties (imagination and/or distinctions of reason) in the very perception of the impressions and ideas of extension. For example, David Fate Norton concludes that "the particular impressions [of extension] are by the imagination transformed into a 'compound impression, which represents extension', or the abstract idea of space itself” (“An Introduction to Hume's Thought”, in The Cambridge Companion to Hume, ed, by David Fate Norton (Cambridge: U. of Cambridge Press, 1993), p. 8; author's emphasis). Yet, this suggestion, that imagination actively constructs the compound impressions of extension, is in no way substantiated by the texts. A complex impression of extension, as a species of sensible impression, "arises in the soul originally, from unknown causes [presumably external causes]" (T 1.1.2.1), with no known role assigned to any higher mental faculty. Hume does allow imagination to play a crucial role in the formulation of the "relations" classified under space and time (e.g., “distance", "contiguous", "above”, "below”, etc.; T 1.1.3-5), but these ideas are more properly classified under the mind's more active capacity to construct abstract ideas (since it involves the "comparing of objects"; T 1.1.5.1), and thus it fails to account for the ideas of extension copied directly from our complex impressions of extension (as will be discussed below). Since it not the subject of this essay to explore all of the postulated reconstructions of Hume's theory of space, the reader would profit from exploring Falkenstein's analysis of the competing approaches (1997, p. 179-201).

6 A number of commentators have strived to interpret Hume's theory of space (and time) as a phenomenalist rendition of Leibniz' relationalist theory, the latter being (possibly) an ontological theory: see, B. Mijuskovic, "Hume on Space (and Time)", Journal of the History of Philosophy, vol. 6, 1977, p. 387-394. It is unclear if Hume was, in fact, inspired by Leibniz, but a much more direct and obvious source for his relationalism/nominalism probably stems from the similar views of Berkeley, especially given the influence that Berkeley's theory of perception and nominalist approach to conceptual abstraction is known to have had on Hume's overall philosophy. See, G. Berkeley, An Essay Towards a New Theory of Vision, in The Works of George Berkeley, Bishop of Cloyne, vol. 1, edited by A. A. Luce and T. E. Jessop (Edinburgh: Thomas Nelson, 1948-1957). In fact, Berkeley describes (tangible) extension, in Leibnizian 
fashion, as "being made up of several distinct co-existent parts" (sec. 145; he then makes the same claim for visible extension).

7 See, P. Bayle, "Zeno of Elea", in The Dictionary Historical and Critical of Mr. Peter Bayle, edited by P. Des Maizeaux, 2nd ed. (New York: Garland Publishing, 1984 (1738)), p. 605-619; G. Berkeley, A Treatise Concerning the Principles of Human Knowledge, in ibid., vol. 2, sec. 124. The literature on Hume's rejection of infinite divisibility is vast, and largely accounts for the recent upsurge in interest in Hume's theory of space and time. For earlier treatments of this topic (in addition to Broad), see, for example: A. Flew, "Infinite Divisibility in Hume's Treatise”, in Hume: A Re-evaluation, edited by D. W. Livingston and J. T. King (New York: Fordham University Press, 1976), p. 257-269; N. Kemp Smith, The Philosophy of David Hume (London: Macmillan, 1941), p. 287. For a few recent, and important, surveys of these issues (in addition to those cited above), see: M. Frasca-Spada, "Some Features of Hume's Conception of Space", Studies in History and Philosophy of Science, vol.21, 1990, p. 371-411; J. Frankin, "Achievements and Fallacies in Hume's Account of Infinite Divisibility”, Hume Studies, vol. 20, 1994, p. 85-101; D. Baxter, “Hume on Infinite Divisibility”, History of Philosophy Quarterly, vol. 5, 1988, p. 133-140; and T. Holden, “Infinite Divisibility and Actual Parts in Hume's Treatise”, Hume Studies, 28, 2002, p. 3-25. It should be noted at this point that the debate on infinite divisibility of extension does not seriously impact the conclusions reached in this essay.

8 A fairly clear statement of the composite hypothesis can be found in Berkeley, as well as the appeal to indivisible minimals of visible and tangible figure: "Each of these magnitudes [visible and tangible] are greater or lesser, according as they contain in them more or fewer points, they being made up of points or minimums" (New Theory of Vision), sec. 54. However, like Hume (as will be argued below), Berkeley does not discuss how his individual minimals can combine to provide a magnitude for the whole extended figure.

9 D. Owen, Hume's Reason (Oxford: Oxford University Press, 1999), p. 84. 
10 Owen has provided a careful analysis of Hume's use of the faculty of imagination, and while judgments of demonstrative and probable reasoning are at times associated with imagination, intuition does not appear to fall under this category (see, T 1.4.7.7—yet, in other contexts, Hume strives to separate demonstrative and probable reasoning from the imagination, especially $\mathrm{T} 1.3 .9 .19$, fn.). Owen's overall judgment of this issue would also seem to support our conclusion, since Hume's explanations of imagination and intuition are kept separate: "I take all this to be further evidence of Hume's lack of commitment to faculty talk: the important point is not which faculty an activity occurs in, but the general principles which explain that activity" (66).

11 If one returns to the distinction between impressions and ideas, then there exists an intriguing possibility for resurrecting the composite hypothesis in the wake of the problems just discussed. Bearing in mind that Hume specifically declares that a complex impression can contain information not copied in our corresponding ideas ( $\mathrm{T}$ 1.1.1.4), one can thus claim that our impressions of spatial magnitude uphold the composite hypothesis (such that magnitude is directly correlated to the summation of the aggregate points), but that our ideas of magnitude copied from those impressions do not. That is, somehow the composite hypothesis, or our mind's ability to recall using it, is lost in the act of copying the information embodied in the impressions to the corresponding ideas. Consequently, the lost information would explain why the mind cannot compute the aggregate points needed to ascertain the magnitude of the ideas of sensible figure. Despite the ingenuity of this stratagem for rescuing the composite hypothesis, it still fails to account for the mind's actual ability to determine the magnitude of spatial ideas, which apparently are grasped in an intuitive fashion.

12 For a nice discussion of these foundational debates in mathematics, especially as they pertain to the Early Modern empiricist tradition, see: D. M. Jesseph, Berkeley's Philosophy of Mathematics (Chicago: University of Chicago Press, 1993), chap. 3. It should be noted, moreover, that Hume cited both Barrow and Nicolas de Malezieu in presenting his theory of space and geometry, although how well acquainted he was with their work is uncertain. See, M. Frasca-Spada (ibid.) on the historical background to these issues, as well as in Space and the Self in Hume's Treatise (Cambridge: Cambridge University Press, 1998). 
13 In this context, the trend among recent scholars to categorize Hume's approach to geometry as "synthetic a priori", as opposed to "analytic a priori", becomes all the more clear. Hume does not regard all geometric truths as analytic, as is evident in both the Enquiry (An Enquiry Concerning Human Understanding, edited by L. A. Selby-Bigge (Oxford: Clarendon Press, 1973), p. 163) and the Treatise. In the latter work, with respect to the claim that "a right line is the shortest distance between two points", he comments (in Kantian fashion) that "this is more properly the discovery of one of the properties of a right line, than just a definition of it", which suggests a synthetic reading (T 1.2.4.26). Moreover, although all ideas stem from sense experience, it is nevertheless the case that, once we obtain various sense ideas, our mind is able to ascertain invariant and irrefutably true relationships among these ideas. Algebra and arithmetic (and some geometry, as will be discussed below) fall within this classification, hence these certain truths could be classified as "a priori". Of course, this type of a priori is quite different from, say, the Cartesian notion (which is prior to, and independent of, sense perception). Nevertheless, Hume's claim of a "discovery" seems to move in a Kantian direction, for once we obtain the knowledge of the invariant (arithmetical/geometric) relationships among certain sense ideas (such as "the shortest distance between two points is a straight line"), that knowledge will be true of all of our possible, future sense experience (pertaining to points and lines, etc.) — and this is at least one possible way to interpret Kant's understanding of the a priori. The synthetic a priori reading of Hume is convincingly argued for by D. P. Coleman, "Is mathematics for Hume Synthetic a Priori?”, Southwestern Journal of Philosophy, vol. 10, 1979, p. 113126, and R. Newman, "Hume on Space and Geometry”, Hume Studies, vol. 7, 1981, p. 1-31.

14 If this rendering of the various discussions and arguments in the Treatise is at all correct (and it is uncertain given the paltry references to mathematics), then it leaves a somewhat ironic ambiguity at the heart of Hume's theory of the foundations of mathematics: first, since the indivisible sensible points provide the nominalist basis for our concepts of number, arithmetic cannot thus provide the foundations for geometry (since arithmetic is thus no more basic than geometry); but, second, since the indivisibles are extensionless (i.e., have no shape or surface, as argued above), they cannot really be classified as more geometric in nature than arithmetic, and thus geometry cannot be regarded as the indisputable grounds of 
arithmetic either. Accordingly, the peculiar attributes of Hume's indivisible minimal points would seem to elude the entire arithmetic-geometry priority dispute!

15 I would like to thank members of the Mid-Atlantic Seminar in Early Modern Philosophy (held at Johns Hopkins University, May 2003) for their helpful comments on an earlier version of this paper presented at the seminar. I would especially like to thank Lorne Falkenstein for his insightful comments and generous help in the development of this project. 